\title{
GAMBARAN KEPUASAN IBU HAMIL TERHADAP PELAYANAN ANC DI KLINIK PRATAMA NIAR KABUPATEN DELI SERDANG TAHUN 2018
}

\author{
Masnila Siregar ${ }^{1}$, Novi Yessi Fransiska Harianja ${ }^{2}$ \\ Program Studi DIII Keperawatan Politeknik Kesehatan Kemenkes Medan \\ Email : yessiharianja18@gmail.com
}

\begin{abstract}
Abstrak
Latar Belakang : Kepuasan pasien adalah suatu tingkat perasaan pasien yang timbul sebagai akibat dari kinerja layanan kesehatan yang diperolehnya setelah pasien membandingkannya dengan apa yang diharapkannya. (Pohan, Imbalo S, 2017). Antenatal care atau pemeriksaan kehamilan adalah serangkaian pemeriksaan yang dilakukan secara berkala dari awal kehamilan hingga proses persalinan untuk memonitor kesehatan ibu dan janin agar tercapai kehamilan yang optimal. Pemeriksaan kehamilan sangat disarankan bagipara ibu hamil agar kesehatan ibu dan janin terus terpantau (Hutahaean serri, 2013). Tujuan Penelitian : Penelitian ini bertujuan untuk mengetahui tingkat kepuasan ibu hamil terhadap pelayanan antenatal care (ANC) di Klinik Pratama Niar Patumbak Kabupaten Deli Serdang Tahun 2018. Metode Penelitian : Adapun desain penelitian yang digunakan adalah Cross-Sectional. Pengukuran tingkat kepuasan menggunakan instrumen dalam bentuk kuesioner. Pengambilan sampel dengan menggunakan teknik accidental sampling, didapatkan 39 responden. Pengumpulan data dilakukan dengan menggunakan kuesioner. Data yang terkumpul diolah dan dianalisis dengan menggunakan komputerisasi program statistik (SPSS). Analisa data mencakup analisis univariat dengan mencari hasil data distribusi frekuensi. Hasil Penelitian: Menunjukkan bahwa kepuasan ibu hamil terhadap pelayanan ANC berdasarkan kehandalan (reliability) 84,6\%, ketanggapan (resposiveness) 92,3\%, buktifisik (tangible) 89,7\%, keramahan (emphaty) 97,4\%, jaminan (assurance) 87,2\%. Kesimpulan: Berdasarkan hasil penelitian ini diharapkan kepada ibu agar lebih meningkatkan pengetahuan tentang ANC dan kesehatan ibu hamil dengan banyak mengikuti penyuluhan - penyuluhan kesehatan dan banyak membaca informasi kesehatan tentang kesehatan ibu hamil.
\end{abstract}

Kata kunci : Kepuasan, Ibu hamil, Antenatal Care

\section{PENDAHULUAN}

Kepuasan pasien adalah suatu tingkat perasaan pasien yang timbul sebagai akibat dari kinerja layanan kesehatan yang diperolehnya setelah pasien membandingkannya dengan apa yang diharapkannya. (Pohan, Imbalo S, 2017).

Kemampuan pelayanan kesehatan suatu negara antara lain diniai dengan perbandingan tinggi rendahnya angka kematian ibu (AKI). (Depkes RI, 2008). Berdasarkan Survei Demografi dan Kesehatan Indonesia (SDKI) angka kematian ibu sudah mengalami penurunan pada periode tahun 1994 - 2011 yaitu pada tahun 1994 sebesar 390 per 100.000 kelahiran hidup, tahun 1997 sebesar 334 per 100.000 kelahiran hidup, tahun 2002 sebesar 307 per 100.000 kelahiran hidup, tahun 2007 sebesar 228 per 100.000 kelahiran hidup namun pada tahun 2012 angka kematian ibu meningkat kembali menjadi sebesar 359 per 100.000 kelahiran hidup. (SDKI, 2014). Berdasarkan data Survei Penduduk Antar Sensus (SUPAS) 2015 angka kematian ibu (AKI) menunjukkan penurunan (AKI 305/100.000 KH).
Berdasarkan laporan Profil Kesehatan Kabupaten / Kota di Sumatra Utara sebesar 268 per 100.000 kelahiran hidup, namun mengalami penurunan pada tahun 2014, angka kematian ibu (AKI) di Sumatra Utara hanya 75 per 100.000 kelahiran hidup (Profil Kesehatan Sumut, 2014).

Penyebab angka kematian yang tinggi menurut Wiknjosastro H dalam Sakinah dan Fibriana tahun 2015, akibat masih kurangnya pengetahuan mengenai sebab akibat dan penanggulangan komplikasi-komplikasi penting dalam kehamilan, persalinan, nifas, serta kurangnya pelayanan kesehatan untuk semua ibu hamil, yaitu pelayanan antenatal care.

Secara Nasional saat ini cakupan pelayanan antenatal care baik dari segi kuantitas maupun kualitas masih tergolong rendah, hal ini disebabkan karena jumlah petugas pengelola dan pelaksanaan program kesehatan ibu dan anak (KIA) di Puskesmas di rasakan masih kurang, disamping itu terbatasnya pengetahuan, keterampilan, sarana yang tersedia serta masih rendahnya pemanfaatan sarana istitusi oleh masyarakat (Suparta, 2007).

Menurut Dinas Kesehatan Sumatra Utara (2012), antenatal care merupakan pelayanan kesehatan profesional (Dokter spesialis obgyn, Dokter Umum, Bidan, Perawat), 
selama kehamilan sesuai dengan pedoman pelayanan antenatal yang dititik beratkan pada kegiatan promotif dan prefentif.

Penilitian dari Dewi Riastawaty dan Sondang tentang Gambaran Tingkat Kepuasan Ibu Hamil Terhadap Pelayanan Antenatal Care di Puskesmas Talang Bakung Kota Jambi Tahun 2012, menyimpulkan bahwa sebanyak 17 responden (41,5\%) puas terhadap pelayanan antenatal care, dan sebanyak 24 responden (58,5\%) kurang puas terhadap pelayanan antenatal care. Sebanyak 25 responden (61,0\%) interaksi bidan dengan ibu hamil baik, dan sebanyak 16 responden (39,0\%) interaksi bidan dengan ibu hamil kurang baik. Sebanyak 19 responden (46,3\%) informasi bidan dengan ibu hamil baik, dan sebanyak 22 responden (53,7\%) informasi bidan dengan ibu hamil kurang baik.

Berdasarkan hasil penelitian Winarni tentang Kepuasan Ibu Hamil Terhadap Pelayanan Antenatal Care (ANC) Oleh Bidan Di Wilayah Kerja Puskesmas Ngoresan Tahun 2014, menyimpulkan bahwa tingkat kepuasan ibu hamil ditinjau dari indikator sarana dan prasarana mayoritas puas 52 (67,5\%). Tingkat kepuasan ibu hamil ditinjau dari indikator tenaga kesehatan mayoritas sangat puas 72 (93,5\%). Tingkat kepuasan ibu hamil ditinjau dari indikator standar pelayanan minimal ANC (7T) sebagian besar responden sangat puas 41 (53,2\%).

Berdasarkan hasil survei pendahuluan yang dilakukan diklinik Pratama Niar Patumbak kabupaten Deli Serdang pada 6 orang ibu hamil yang diwawancarai diketahui 2 orang ibu hamil mengatakan bahwa pasien datang untuk periksa kehamilan agar bayinya lahir sehat, 1 orang ibu mengatakan melakukan pemeriksaan kehamilan jika ada keluhan saja tapi kurang direspon cepat oleh petugas kesehatan, 2 orang ibu hamil yang lainnya terkadang malas untuk datang periksa kehamilan sedangkan 1 orang ibu hamil lainnya mengatakan melakukan pemeriksaan kehamilan hanya ikut - ikutan saja tanpa mengetahui tujuan dan manfaat pemeriksaan kehamilan (ANC) karena tidak dijelaskan secara detail oleh petugas kesehatan . Dalam hal ini dapat disimpulkan bahwa pengetahuan ibu hamil tentang pemeriksaan kehamilan masih dapat dikatakan rendah karena informasi yang diberikan mengenai ANC juga kurang dan dapat dijadikan catatan penyebab menurunnya kunjungan yang dilakukan oleh ibu hamil.

Berdasarkan buku rawatan Klinik Pratama Niar Patumbak Kabupaten Deli Serdang didapatkan kunjungan ibu hamil dalam 6 bulan terakhir (juli sampai dengan desember 2017) sebayak 340 ibu hamil dan pemeriksaan kehamilan 940 kali pemeriksaan kehamilan (ANC), ibu yang melakukan persalinan 300 ibu. Menurut WHO pemeriksaan kehamilan (ANC) dilakukan minimal 4 kali pemeriksaan selama kehamilan, maka pemeriksaan kehamilan di Klinik Pratama Niar Patumbak Kabupaten Deli Serdang seharusnya kurang lebih 1360 kali pemeriksaan kehamilan.

Berdasarkan latar belakang tersebut penulis tertarik untuk mengetahui tingkat kepuasan ibu hamil terhadap pelayanan ANC di klinik Pratama Niar Patumbak Kabupaten Deli Serdang

\section{METODE PENELITIAN}

Adapun desain penelitian yang digunakan dalam penelitian ini adalah desain penelitian cross-sectional yaitu melakukan observasi atau pengukuran variabel sekali dan sekaligus pada waktu yang sama (Riyanto. A, 2015).

Populasi dalam penelitian ini adalah seluruh ibu hamil terimster I,II,III yang melakukan pemeriksaan kehamilan di Klinik Pratama Niar Patumbak Kabupaten Deli Serdang pada Juli - Desember 2017 sebanyak 340 orang ibu hamil.

Dalam penelitian ini yang menjadi sampel adalah sebagian dari populasi yang diambil dengan cara accidental sampling. Accidental sampling cara pengambilan sampel dengan mengambil responden atau kasus yang kebetulan ada dan tersedia (Riyanto, A 2015).

Instrumen yang digunakan dalam penelitian ini dengan menggunakan kuisioner yang terdiri dari 20 pernyataan tertulis yang digunakan untuk memperoleh informasi dari responden.

HASIL

Tabel 4.1 Distribusi $\quad$ Frekuensi $\quad$ Karakteristik Responden Terhadap Pelayanan ANC di Klinik Pratama Niar Patumbak Kabupaten Deli Serdang Tahun 2018

\begin{tabular}{cc|c|c}
\hline Karakteristik & Kategori & $\mathbf{N}$ & $\mathbf{\%}$ \\
\hline \multirow{2}{*}{ Usia } & $17-24$ & 18 & 46,2 \\
\cline { 2 - 4 } & $25-32$ & 15 & 38,5 \\
\cline { 2 - 4 } Total & $33-40$ & 6 & 15,4 \\
\cline { 2 - 4 } & & 39 & 100 \\
\hline \multirow{2}{*}{ Pendidikan } & SMP & 7 & 17,9 \\
\cline { 2 - 4 } & SMA & 27 & 69,2 \\
\cline { 2 - 4 } Total & Perguruan & 5 & 12,8 \\
& Tinggi & 39 & 100,0 \\
\cline { 2 - 4 } Pekerjaan & & 14 & 35,9 \\
\cline { 2 - 4 } Total & Bekerja & 25 & 64,1 \\
\cline { 2 - 4 } & Tidak Bekerja & 39 & 100,0 \\
\hline \multirow{2}{*}{ Paritas } & & 20 & 51,3 \\
\cline { 2 - 4 } Total & Primigravida & 19 & 48,7 \\
\cline { 2 - 4 } & Multigravida & 100,0 \\
\hline
\end{tabular}

Berdasarkan tabel 4.1 dapat diketahui dari $39 \mathrm{ibu}$ hamil mayoritas berumur 17 - 24 tahun sebanyak 18 orang (46,2\%), pendidikan terbesar adalah SMA sebanyak 27 orang $(69,2 \%)$, sebagian besar ibu tidak bekerja sebanyak 25 orang (64,1\%), sedangkan parietas terbanyak adalah primigravida sebanyak 20 orang (51,3\%) diikuti multigravida sebanyak 19 orang (48,7\%). 
Tabel 4.2 Distribusi $\quad$ Frekuensi $\quad$ Responden

Berdasarkan Kepuasan Ibu Hamil

Terhadap Pelayanan ANC di Klinik

Pratama Niar Patumbak Kabupaten Deli

Serdang Tahun 2018

\begin{tabular}{c|c|c|c}
\hline Kepuasan & Kategori & $\mathbf{N}$ & $\mathbf{\%}$ \\
\hline Seluruh Dimensi & Tidak Puas & 6 & 15,4 \\
Kepuasan & Puas & 33 & 84,6 \\
\hline & Total & $\mathbf{3 9}$ & $\mathbf{1 0 0}$ \\
\hline
\end{tabular}

Berdasarkan tabel 4.2 dapat diketahui dari 39 ibu hamil mayoritas merasa puas berdasarkan keseluruhan dimensi kepuasan mayoritas merasa puas sebanyak 33 orang $(84,6 \%)$ dan merasa tidak puas sebanyak 6 orang $(15,4 \%)$.

Tabel 4.3 Distribusi Frekuensi Responden Berdasarkan Kehandalan (Reliability) di Klinik Pratama Niar Patumbak Kabupaten Deli Serdang Tahun 2018

\begin{tabular}{c|c|c|c}
\hline No & Kehandalan & $\mathbf{N}$ & $\mathbf{\%}$ \\
\hline 1 & Tidak Puas & 6 & 15,4 \\
2 & Puas & 33 & 84,6 \\
\hline & Total & $\mathbf{3 9}$ & $\mathbf{1 0 0 , 0}$ \\
\hline
\end{tabular}

Berdasarkan tabel 4.3 dapat diketahui dari $39 \mathrm{ibu}$ hamil sebagian merasa puas sebanyak 36 orang (92,3\%) dan merasa tidak puas sebanyak 3 orang $(7,7 \%)$.

\begin{tabular}{c|c|c|c} 
Tabel 4.4 & $\begin{array}{l}\text { Distribusi Frekuensi } \\
\text { Berdasarkan } \\
\text { (Responsiveness) di Klinik Pratama Niar } \\
\text { Patumbak Kabupaten } \\
\text { Tahun 2018 }\end{array}$ & $\begin{array}{r}\text { Responden } \\
\text { Ketanggapan }\end{array}$ \\
\begin{tabular}{|c|c|c} 
Serdang \\
No
\end{tabular} & Ketanggapan & N & \% \\
\hline 1 & Tidak Puas & 3 & 7,7 \\
2 & Puas & 36 & 92,3 \\
\hline & Total & $\mathbf{3 9}$ & $\mathbf{1 0 0}$ \\
\hline
\end{tabular}

Berdasarkan tabel 4.4 dapat diketahui dari $39 \mathrm{ibu}$ hamil sebagian merasa puas sebanyak 36 orang (92,3\%) dan merasa tidak puas sebanyak 3 orang $(7,7 \%)$.

Tabel 4.5 Distribusi Frekuensi Responden Berdasarkan Bukti fisik (Tangible) di Klinik Pratama Niar Patumbak Kabupaten Deli Serdang Tahun 2018

\begin{tabular}{c|c|c|c}
\hline No & Bukti Fisik & $\mathbf{N}$ & $\mathbf{\%}$ \\
\hline 1 & Tidak Puas & 4 & 10,3 \\
2 & Puas & 35 & 89,7 \\
\hline & Total & $\mathbf{3 9}$ & $\mathbf{1 0 0 , 0}$ \\
\hline
\end{tabular}

Berdasarkan tabel 4.5 dapat diketahui dari $39 \mathrm{ibu}$ hamil sebagian merasa puas sebanyak 35 orang $(89,7 \%)$ dan merasa tidak puas sebanyak 4 orang (10,3\%).
Tabel 4.6 Distribusi Frekuensi Responden Berdasarkan Keramahan (Empathy) di Klinik Pratama Niar Patumbak Kabupaten Deli Serdang Tahun 2018

\begin{tabular}{c|c|c|c}
\hline No & Keramahan & $\mathbf{N}$ & $\mathbf{\%}$ \\
\hline 1 & Tidak Puas & 1 & 2,6 \\
\cline { 2 - 4 } 2 & Puas & 38 & 97,4 \\
\hline & Total & $\mathbf{3 9}$ & $\mathbf{1 0 0 , 0}$ \\
\hline
\end{tabular}

Berdasarkan tabel 4.6 dapat diketahui dari $39 \mathrm{ibu}$ hamil sebagian merasa puas sebanyak 38 orang $(97,4 \%)$ dan merasa tidak puas sebanyak 1 orang (2,6\%).

Tabel 4.7 Distribusi $\quad$ Frekuensi $\quad$ Responden Berdasarkan Jaminan (Assurance) di Klinik Pratama Niar Patumbak Kabupaten Deli Serdang Tahun 2018

\begin{tabular}{c|c|c|c}
\hline No & Jaminan & $\mathbf{N}$ & $\mathbf{\%}$ \\
\hline \multirow{2}{*}{1} & Tidak Puas & 5 & 12,8 \\
\cline { 2 - 4 } 2 & Puas & 34 & 87,2 \\
\hline & Total & $\mathbf{3 9}$ & $\mathbf{1 0 0 , 0}$ \\
\hline
\end{tabular}

Berdasarkan tabel 4.7 dapat diketahui dari 39 ibu hamil sebagian merasa puas sebanyak 34 orang $(87,2 \%)$ dan merasa tidak puas sebanyak 5 orang $(12,8 \%)$.

\section{PEMBAHASAN}

\section{Berdasarkan Karakteristik Responden}

Umur adalah lama hidup seseorang yang dihitung dari jumlah ulang tahun mulai saat dilahirkan sampai saat dilakukan penelitian (Notoatmodjo, 2012). Berdasarkan tabel 4.1 dapat diketahui ibu hamil mayoritas berumur 17 24 tahun sebanyak 18 orang (46,2\%). Umur dapat mempengaruhi pendidikan pola pikir manusia, semakin cukup umur maka tingkat kematangan dan pengalaman seseorang akan lebih matang dalam berfikir, dengan adanya kemajuan teknologi maka pola pikir manusia akan lebih maju dan semakin kritis (Winarni, 2014).

Pendidikan adalah jalur yang terstruktur dan berjenjang yang terdiri atas pendidikan dasar, menengah dan perguruan tinggi. Responden mayoritas berpendidikan SMA sebanyak 27 orang (69,2\%). Responden yang berpendidikan menengah ke atas akan lebih mudah untuk menerima informasi dan lebih tanggap dalam memberikan pendapatnya dari pelayanan kesehatan dibandingkan dengan yang berpendidikan menengah ke bawah (Winarni, 2014).

Pekerjaan adalah kegiatan ekonomi yang dilakukan seseorang dengan maksud memperoleh pendapatan. Responden mayoritas tidak bekerja sebanyak 25 orang (64,1\%). Responden yang memiliki penghasilan menengah ke atas akan mempengaruhi responden untuk memilih tempat pelayanan kesehatan yang berkualitas dan bagus, sedangkan responden yang berpenghasilan menengah ke bawah akan memilih tempat pelayanan kesehatan yang harga atau biayanya lebih murah walaupun pelayanannya tidak sesuai dengan harapan (Winarni, 2014). Dari hasil tersebut tergambar bahwa pengguna 
pelayanan Klinik Pratama Niar Patumbak Kabupaten Deli Serdang masih didominasi oleh masyarakat dengan pendidikan menengah dan tidak bekerja.

Paritas adalah banyaknya jumlah kelahiran hidup yang dialami oleh seorang wanita (Winarni, 2014). Responden mayoritas parietas primigravida sebanyak 20 orang (51,3\%) diikuti multigravida sebanyak 19 orang (48,7\%). Ibu dengan jumlah paritas yang tinggi tidak terlalu khawatir dengan kehamilannya lagi sehingga menurunkan angka kunjungannya, sedangkan ibu dengan kehamilan pertama (primigravida) merasa ANC merupakan sesuatu yang baru sehingga ibu memiliki motivasi yang lebih tinggi dalam pelaksanaannya.Penelitian ini sejalan dengan penelitian yang dilakukan oleh Niki Andika Wulan Sari, tentang "Gambaran Kepuasan Ibu Hamil Pada Pelayanan Antenatal Care Terintegrasi Di Puskesmas Temon II Kulon Progo Tahun 2017 “ yang menyatakan bahwa sebagian besar responden berumur 20 - 35 tahun sebanyak 43 responden (82,7\%), dengan 26 responden (50\%) merasa puas dan 17 responden (32,7\%) merasa tidak puas dengan pelayanan antenatal care terintegrasi. Ibu hamil sebagian besar mempunyai pendidikan SMA sebanyak 35 responden (67,3\%), dengan 24 responden (46,2\%) merasa puas dan 11 responden (21,2\%) merasa tidak puas dengan pelayanan antenatal care terintegrasi. Ibu hamil sebagian besar tidak bekerja sebanyak 35 responden (67,3\%), dengan 25 responden (48,1\%) merasa puas dan 10 responden (19,2\%) merasa tidak puas dengan pelayanan antenatal care terintegrasi.

\section{Berdasarkan Keseluruhan Dimensi Kepuasan}

Kepuasan pasien adalah suatu tingkat perasaan pasien yang timbul sebagai akibat dari kinerja layanan kesehatan yang diperolehnya setelah pasien membandingkannya dengan apa yang diharapkannya (Pohan, Imbalo S, 2017). Kepuasan pengguna jasa layanan kesehatan akan dipengaruhi oleh beberapa faktor seperti sikap peduli, biaya, bukti fisik, jaminan, keramahan, kehandalan, dan kecepatan dalam memberikan tanggapan terhadap keluhan pasien (Walyani dan Puroastuti, 2015).

Berdasarkan tabel 4.2 dapat diketahui dari 39 ibu hamil mayoritas merasa puas sebanyak 33 orang $(84,6 \%)$ dan merasa tidak puas sebanyak 6 orang (15,4\%). Dalam penelitian ini Klinik Pratama Niar Patumbak Kabupaten Deli Serdang sebagian besar sudah memenuhi harapan pasien seperti sikap komunikasi yang baik antara petugas dengan pasien, sudah memiliki alat - alat yang cukup untuk mendukung pemeriksaan, dan biaya pemeriksaan yang tidak berlebihan.

\section{Berdasarkan Kehandalan (Reliability)}

Kehandalan adalah kemampuan petugas kesehatan melaksanakan pelayanannya (reliability). Kemampuan petugas dalam pemeriksaan fisik, obstetri, laboratorium, status gizi dan pemberian tablet tambah darah (Wawan dan Dewi, 2017).

Berdasarkan tabel 4.3 dapat diketahui dari 39 ibu hamil mayoritas merasa puas sebanyak 33 orang $(84,6 \%)$ dan merasa tidak puas sebanyak 6 orang $(15,4 \%)$, dihasilkan pada pernyataan "Petugas kesehatan selalu memberikan pelayanan antenatal care sesuai jadwal (pemberian tablet penambah darah)”.

Penelitian ini sejalan dengan hasil penelitian yang dilakukan Niki Andika Wulan Sari, tentang Gambaran Kepuasan Ibu Hamil Pada Pelayanan Antenatal Care Terintegrasi Di Puskesmas Temon II Kulon Progo Tahun 2017, menyimpulkan bahwa ibu hamil yang merasa puas sebanyak 48 responden (92,3\%) dan 4 responden (7,7\%) merasa tidak puas dengan Kehandalan (Reliability) tenaga kesehatan dalam pelayaan antenatal care di Puskesmas Temon II Kulon Progo .

Pengamatan peneliti pada persepsi kualitas pelayanan ANC seperti pengukuran fundus uteri, tahapan pengukuran dimulai dari pemeriksaan leopold dan denyut jantung janin. Pemeriksaan Leopold : petugas kesehatan tidak memberi tahu tujuan pemeriksaan leopold dan saat menggoyangkan perut ibu tanpa menanyakan apakah ibu merasa kesakitan atau tidak. Pemeriksaan Denyut Jantung Janin (DJJ) : perut ibu ditekan dengan alat periksa (funanduscope) dan mungkin akan terasa tertekan. Petugas kesehatan seharusnya bertanya apakah ibu merasa sakit, tetapi hal tersebut tidak mereka lakukan.

Pelayanan tersebut diatas adalah salah satu hal yang dapat menyebabkan ketidakpuasan pasien sehingga pada waktu yang akan datang pasien tidak akan datang kembali untuk mendapatkan pelayanan.

\section{Berdasarkan Ketanggapan(Responsiveness)}

Kecepatan tanggapan petugas kesehatan terhadap kebutuhan pasien (responsiveness). Berupa kecepatan tindakan terhadap kebutuhan ibu hamil, penanganan perawatan yang cepat, tepat dan bersahabat, perhatian terhadap ibu hamil dalam pelayanan antenatal care (Wawan dan Dewi, 2017).

Berdasarkan tabel 4.4 dapat diketahui dari 39ibu hamil sebagian besar merasa puas sebanyak 36 orang (92,3\%) pada aspek prosedur penyampaian informasi yang tidak berbeli - belit dan mudah dimengerti dalam mendapatkan pelayanan antenatal care dan merasa tidak puas sebanyak 3 orang $(7,7 \%)$ dihasilkan pada pernyataan "Petugas kesehatan segera melakukan pelayanan ketika ibu hamil tiba di ruang pemeriksaan”.

Penelitian ini sejalan dengan hasil penelitian yang dilakukan Adam tentang Kepuasan Masyarakat Terhadap Pelayanan Puskesmas di Wilayah Timur Indonesia Tahun 2006, menyimpulkan bahwa sebagian besar masyarakat menilai kepuasan terhadap pelayanan kesehatan di puskesmas yang disebabkan oleh faktor ketanggapan petugas memiliki 2,7 kali terhadap kunjungan ulang sebagai kompensasi atas kepuasannya.

\section{Berdasarkan Bukti fisik (Tangible)}

Berupa bukti fisik yang dapat dilihat yang meliputi gedung, perlengkapan, seragam, kerapian petugas kesehatan dan sarana komunikasi (Wawan dan Dewi, 2017). 
Berdasarkan tabel 4.5dapat diketahui dari $39 \mathrm{ibu}$ hamil sebagian merasa puas sebanyak 35 orang $(89,7 \%)$ dan merasa tidak puas sebanyak 4 orang $(10,3 \%)$ dihasilkan pada pernyataan "Petugas kesehatan mencuci tangan sebelum melayani ibu hamil dan kelengkapan alat alat yang digunakan saat pelayanan ANC.

Penelitian ini sejalan dengan hasil penelitian yang dilakukan Niki Andika Wulan Sari, tentang Gambaran Kepuasan Ibu Hamil Pada Pelayanan Antenatal Care Terintegrasi Di Puskesmas Temon II Kulon Progo Tahun 2017, menyimpulkan bahwa, ibu hamil yang merasa puas sebanyak 51 responden $(98,1 \%)$ dan 1 responden $(1,9 \%)$ merasa tidak puas dengan bukti fisik (tangibles) dalam pelayanan antenatal care terintegrasi di Puskesmas Temon II Kulon Progo.

Menurut Yamit, 2001 bahwa kepuaan konsumen terhadap suatu produk tergantung dengan bukti langsung yang didapatkan seperti kelengkapan alat, kapasitas kualitas produk dan dukungan peralatan yang baik.

\section{Berdasarkan Keramahan (Empathy)}

Keramahan, pengetahuan dan citra petugas kesehatan (empathy). Berupa keramahan dan kesopanan petugas kesehatan yang langsung menyapa pasien dan menanyakan keluhan pada saat pelayanan antenatal care, pengetahuan dan keterampilan petugas kesehatan dalam pelayanan antenatal care, citra dan prestasi petugas kesehatan (Wawan dan Dewi, 2017)

Berdasarkan tabel 4.6 dapat diketahui dari 39 ibu hamil sebagian merasa puas sebanyak 38 orang $(97,4 \%)$ pada aspek pelayanan yang tidak memandang status pasien yang dibuktikan oleh ibu hamil yang sebagian besar menggunakan jaminan kesehatan (BPJS) tetapi tetap mendapatkan pelayanan antenatal care yang tidak berbeda dengan ibu hamil yang membayar langsung dalam pemeriksaan, dan merasa tidak puas sebanyak 1 orang (2,6\%) dihasilkan dari pernyataan "Petugas kesehatan langsung menyapa ibu hamil dan menanyakan keluhan pada saat melakukan pelayanan,

Penelitian ini sejalan dengan hasil penelitian yang dilakukan Rikhly Faradisy Mursyida dkk tentang Kepuasan Ibu Hamil Dan Persepsi Kualitas Pelayanan Antenatal Care Di Puskesmas Tanjung Kabupaten Sampang Madura Tahun 2012 menyimpulkan bahwa Empathy mempunyai hubungan yang sangat bermakna dengan kepuasan $(p=0,0001<0,01)$. Pola hubungan yang yang terjadi adalah responden dengan persepsi emphaty baik cenderung puas $11(82,2 \%)$ sebalikanya responden dengan persepsi empathy baik cenderung tidak puas $(97,7 \%)$.

Menurut (Yamit, 2001) bahwa sikap loyalitas pelanggan selalu berbanding lurus dengan kepuasan yang di dapatkan dari adanya rasa perhatian yang baik dari pemberi jasa, yang menunjukkan bahwa dengan adanya rasa kepuasan yang baik pada pelanggan maka pelanggan akan memutuskan untuk kembali atau membeli jasa yang pernah di dapatkan. Dengan demikian adanya empati atau perhatian yang baik akan memberi kepuasan kepada pasien yang selanjutnya menyebabkan pasien memutuskan dan memanfaatkan pelayanan.

\section{Berdasarkan Jaminan (Assurance)}

Kepedulian petugas kesehatan dalam memberikan pelayanan (assurance). Berupa kemudahan petugas kesehatan untuk dihubungi pada saat dibutuhkan, komunikasi petugas kesehatan pada pasien, kepedulian perawat untuk meningkatkan pelayanan antenatal care.

Berdasarkan tabel 4.7 dapat diketahui dari 39 ibu hamil sebagian merasa puas sebanyak 34 orang $(87,2 \%)$ ditinjau dari penarikan tarif biaya sesuai dengan kualitas pelayanan yang diberikan, petugas kesehatan yang berpengalaman dan merasa tidak puas sebanyak 5 orang $(12,8 \%)$ dihasilkan dari pernyataan "Kemudahan petugas kesehatan untuk dihubungi pada saat dibutuhkan”.

Penelitian ini sejalan dengan hasil penelitian yang dilakukan Rikhly Faradisy Mursyida dkk tentang Kepuasan Ibu Hamil Dan Persepsi Kualitas Pelayanan Antenatal Care Di Puskesmas Tanjung Kabupaten Sampang Madura Tahun 2012 menyimpulkan bahwa, ada hubungan sangat bermakna antara persepsi assurance dengan kepuasan ibu hamil $\mathrm{p}=0,0001<$ 0,01 . Pola hubungan adalah pada responden dengan persepsi assurance baik cenderung puas (75,6\%) sebaliknya responden dengan persepsi assurance tidak baik cenderung tidak puas (79,5\%).

Menurut Parasuraman dalam Tjiptono menyatakan bahwa jaminan kepastian yang merupakan bagian dari dimensi kualitas pelayanan berpengaruh terhadap harapan pasien atas pelayanan yang diberikan oleh suatu pelayanan kesehatan. Hal ini sesuai dengan hasil penelitian Adam yang menunjukkan bahwa jika pelayanan kesehatan di puskesmas tidak dapat memberikan jaminan mutu yang sesuai dengan harapan ibu hamil maka akan menurunkan kepuasan masyarakat hingga 2,56 kali. Pada akhirnya masyarakat ulang dari pelayanan yang diberikan.

\section{KESIMPULAN}

Dari hasil penelitian yang dilakukan mengenai gambaran kepuasan ibu hamil terhadap pelayanan ANC di Klinik Pratama Niar Kabupaten Deli Serdang Tahun 2018 maka didapat kesimpulan sebagai berikut:

1 Kepuasan ibu hamil berdasarkan kehandalan (reliability) mayoritas merasa puas sebanyak sebanyak 33 orang ( 84,6\%). Semakin tinggi tingkat pengetahuan dan kemampuan petugas tentang antenatal care makin tinggi pula kualitas pelayanan kesehatan yang diberikan pada ibu hamil. Kualitas yang tinggi akan meningkatkan kepuasan pasien, selanjutnya pasien akan berkunjung ulang pada pelayanan yang sama.

2 Kepuasan ibu hamil berdasarkan ketanggapan (responsiveness) mayoritas merasa puas sebanyak 36 orang (92,3\%). Semakin cepat pelayanan dan tindakan yang diberikan dalam menyelesaikan keluhan pasien maka semakin cepat pula keluhan teratasi, selanjutnya kepuasan ibu hamil akan pelayanan antenatal care semakin meningkat.

3 Kepuasan ibu hamil berdasarkan bukti fisik (tangibel) mayoritas merasa puas sebanyak 35orang 
(89,7\%). Kenyamanan fasilitas yang diberikan pada saat pelayanan contohnya kelengkapan alat, ruangan yang sesuai standart berkaitan dengan efektifitas klinis, tetapi dapat mempengaruhi kepuasan pasien dan bersedia untuk kembali ke fasititas pelayanan kesehatan untuk memperoleh pelayanan berikutnya.

4 Kepuasan ibu hamil berdasarkan keramahan (emphaty)mayorits merasa puas sebanyak 38 orang (97,4\%). Kepedulian dan perhatian petugas kesehatan terhadap semua pasien tanpa memandang status sosial ekonomi sehingga terjadi kemudahan penyampaian informasidan mempengaruhi kepuasan pasiendalam mendapatkan pelayanan.

5 Kepuasan ibu hamil berdasarkan jaminan (assurance) mayoritas merasa puas sebanyak 34 orang (87,2\%). Jaminan kesehatan yang tinggi merupakan bagian dari dimensi kualitas pelayanan dan berpengaruh terhadap harapan pasien atas pelayanan yang diberikan oleh suatu pelayanan kesehatan.

\section{SARAN}

1 Kepada ibu hamil diharapkan secara rutin melakukan pemeriksaan antenatal care, agar dapat diketahui perkembangan kehamilannya untuk mencegah terjadinya komplikasi secara dini selama kehamilan.

2 Kepada petugas kesehatan diharapkan dalam memberikan pelayanan antenatal care dapat memberikan pelayanan yang kompherensif seperti memberikan pelayanan antenatal care sesuai jadwal (pemberian tablet penambah darah), waktu yang cepat dalam memberikan pelayanan, petugas kesehatan mencuci tangan sebelum melayani ibu hamil dan kelengkapan alat-alat yang digunakan saat pelayanan ANCmemberikan informasi yang jelas serta rasa empati pada pasien lebih ditingkatkan kembali menjadikan pasien lebih nyaman dan aman terhadap pelayanan yang dilakukan tenaga kesehatan.

3 Kepada peneliti yang akan datang agar penelitian selanjutnya lebih dikembangkan dengan menambah sampel,variabel, dan metode penelitian sehingga diperoleh hasil yang lebih baik mengenai kepuasan ibu hamil terhadap pelayanan ANC.

\section{DAFTAR PUSTAKA}

Arikunto, 2010. Prosedur Penelitian Suatu Pendekatan Praktik.Jakarta

Rineka Cipta

Dewi Riastawaty, Sondang. 2012. Gambaran Tingkat Kepuasan Ibu Hamil Terhadap Pelayanan Antenatal Care di Puskesmas Talang Bakung Kota Jambi, [online] Available at $<$ http://www.jurnal.co.id [accessed 2 Februari 2018]

Hani, Ummi., Marjati, Kusbandiyah Jiarti., Yulifah, Rita. 2010. Asuhan Kebidanan Pada Kehamilan Fisiologis. Jakarta: Salemba Medika
Hutahaean, Serri. 2013. Perawatan Antenatal. Jakarta Selatan: Salemba Medika

Jasmawati, Melly. 2015. Analisis hubungan pengetahuan ibu hamil tentang Antenatal Care debgan perilaku kunjungan pemeriksakan kehamilan di puskesmas sempaja samarinda, [online] Available at $<$ https://husadamahakam.files.wordpress.com/2015 /07/2. [accessed 12 Januari 2018]

Johnson, Y Joyce. 2014. Keperawatan Maternitas. Yogyakarta : Rapha Publishing

Kementrian kesehatan Republik Indonesia. 2014. Profil Kesehatan Indonesia Kabupaten/Kota Sumatra Utara, [online] Available at $<$ http://www.depkes.go.id. [accessed 10 Januari 2018]

Kementrian kesehatan Republik Indonesia. 2015. Profil Kesehatan Indonesia. Jakarta: Kementrian Kesehatan Republik Indonesia.

Kementrian kesehatan Republik Indonesia. 2016. Profil Kesehatan Indonesia, [online] Available at <http://www.depkes.go.id. [accessed 10 Januari 2018]

Muchlisin Riadi. 2016. Pengertian, Cara Mengukur dan Faktor yang Mempengaruhi Kepuasan Pasien, [online] Available at $<$ http://www.kajianpustaka.com/2016/07/pengertia n-cara-mengukur-dan-faktor-yang-mempengaruhikepuasan-pasien. [accessed 1 februari 2018]

Mufdlilah. 2009. ANC Fokus. Yogyakarta: Nuhamedika

Mursyida , Rikhly Faradisy, dkk. 2012. Kepuasan Ibu Hamil Dan Persepsi Kualitas Pelayanan Antenatal Care Di Puskesmas Tanjung Kabupaten Sampang Madura, [online] Available at $<$ http://ejournal.almaata.ac.id. [accessed 1 februari 2018]

Notoatmodjo, Soekidjo. 2012. Metodologi Penelitian Kesehatan. Jakarta : Rineka Cipta

Pohan, Imbalo S, Dr. MPH, MHA. 2017. Jaminan Mutu Layanan Kesehatan. Jakarta : EGC

Politeknik Kesehatan. 2006. Panduan Penyusunan Karya Tulis Ilmiah. Jakarta: Rineka Cipta

RepositoryUSU.repository.usu.ac.id/bitsteam/123456789/3 1677/4/Chapter\%20II. [accessed 1 februari 2018]

Riyanto, A. 2015. Aplikasi Metodologi Penelitian Kesehatan. Yogyakarta: Nuha Medika

Sari , Niki Andika Wulan. 2017. Gambaran Kepuasan Ibu Hamil Pada Pelayanan Antenatal Care Terintegrasi Di Puskesmas Temon II Kulon Progo, [online] Available at $<\underline{\text { http://ejournal.almaata.ac.id. }}$ [accessed 1 februari 2018]

Wawan, A., M, Dewi. 2016. Teori Pengukuran Pengetahuan,Sikap dan Perilaku Manusia. Yogyakarta: Nuha Medika

Winarni. 2014. Kepuasan Ibu Hamil Terhadap Pelayanan Antenatal Care (ANC) Oleh Bidan Di Wilayah Kerja Puskesmas Ngoresan: http://ejournal.almaata.ac.id. [accessed 1 februari 2018] 